International Journal of Current Advanced Research

ISSN: O: 2319-6475, ISSN: P: 2319 - 6505, Impact Factor: SJIF: 5.995

Available Online at www.journalijcar.org

Volume 6; Issue 4; April 2017; Page No. 3541-3544

DOI: http://dx.doi.org/10.24327/ijcar.2017.3544.0311

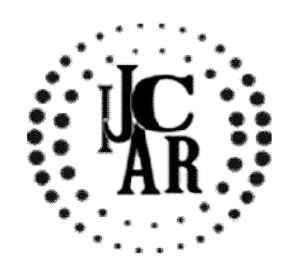

Research Article

\title{
PREVALENCE OF TWO VARIANTS OF PERMANENT MANDIBULAR SECOND PREMOLARS
}

\author{
Priyadharshini $\mathbf{M}^{1^{*}}$ and Don K. R ${ }^{2}$
}

${ }^{1}$ Saveetha Dental College, Chennai-600077, Tamil Nadu, India

${ }^{2}$ Department of Oral and maxillofacial Pathology, Saveetha Dental College, Chennai-600077, Tamil Nadu

\begin{tabular}{l}
\hline A R T I C L E I N F O \\
\hline Article History: \\
Received $12^{\text {th }}$ January, 2017 \\
Received in revised form $27^{\text {th }}$ February, 2017 \\
Accepted $2^{\text {nd }}$ March, 2017 \\
Published online $28^{\text {th }}$ April, 2017 \\
\end{tabular}

Key words:

Cusp forms, groove patterns, permanent mandibular second premolar.

\begin{abstract}
A B S T R A C T
Background: Dental identification is an important identification tool in Forensic odontology. Permanent Mandibular second premolars, though generally are included under bicuspids, are of two types, the 2 cusp and 3 cusp variants. There is a difference of opinion regarding whether ethnicity influences dental morphology or not.
\end{abstract}

Aim: To determine the prevalence of two different occlusal morphological patterns of Permanent mandibular second premolars in Indian population.

Methods: This study was undertaken from the students of Saveetha Dental College, Chennai. A total of 100 students were randomly examined for cuspalvariations and groove patterns of Permanent mandibular second premolars.

Results: Thestudy revealed that the predominant cusp pattern wastwo cusp pattern (55.5\%) and the predominant groove pattern was $\mathrm{Y}$ shaped $(43.5 \%)$. The predominance in the combination of cusp and groove pattern was $2 \mathrm{U}(27.5 \%)$. Among males, the predominant cusp pattern was bicuspid (61\%) and the predominant groove pattern was Y shaped $(45 \%)$. Among females, the predominant cusp pattern was bicuspid $(51 \%)$ and the predominant groove pattern was Y shaped $(41.9 \%)$.

Conclusion: Dental identification is an important identification tool in forensic odontology. It may be concluded that variation in degree of expression and frequency of Permanent mandibular second premolars of different populations is different, which may help in forensic identification.

Copyright $\bigcirc 2017$ Priyadharshini M and Don K. R. This is an open access article distributed under the Creative Commons Attribution License, which permits unrestricted use, distribution, and reproduction in any medium, provided the original work is properly cited.

\section{INTRODUCTION}

The permanent mandibular second premolars are the fifth tooth from the midline and also the succedaneous tooth of deciduous mandibular second molars [1]. In mandibular first premolars, the lingual cusp is not functional but the mandibular second premolars are of two cusp and three cusp varieties [10]. So they are divided into two types namely bicuspid and tricuspid premolars.

There are three different occlusal groove patterns in permanent mandibular second premolars. "Y" shaped pattern is associated with three cusp type variety and " $U$ " shaped, " $H$ " shaped and "Straight groove" pattern are associated with two cusp type variety. The existence of these type of traits unilaterally or bilaterally in the individuals is also of clinical importance as the arch perimeters change when mixed dentition analysis is done to predict the space required for permanent canine, first and second premolars respectively[2,3].

\section{*Corresponding author: Priyadharshini M}

Saveetha Dental College, Chennai-600077, Tamil Nadu, India
This knowledge of morphology can be employed in the fields of forensic odontology, anthropology and odontrometry as it can provide information on the phylogenetic relationship between species as well as variations and diversities within a population $[3,6]$. The permanent mandibular second premolars of three cusp type is relatively larger mesio-distally than the two cusp premolars [7]. So this rare discrepancy in the prediction of leeway space can leads to slight crowding in the permanent dentition. This problem may worsen where there is only unilateral existenceof these type traits, leading to shifting of midline and canine guidelines discrepancy [6]. Degree of expression and frequency of teeth in dentitions of different populations is different, which may help in forensic identification. This study was undertaken to find the prevalence of different occlusal morphological patterns of permanent mandibular 2nd premolars in the South Indian population.

\section{MATERIALS AND METHODOLOGY}

A total of 100 mandibular second premolars were randomly evaluated in this study. The participant consent form and the participant information details were collected. The subjects 
included were students from Saveetha dental college, Chennai, India.

\section{Inclusion Criteria}

1. Permanent mandibular second premolars free from occlusal or proximal caries.

2. Presence of bilaterally completely erupted permanent mandibular second premolars.

3. Permanent mandibular second premolars showing clear occlusal outline with all cusps and groove pattern.

\section{Exclusion Criteria}

1. Participants with restorations and prosthesis in the permanent mandibular second premolars.

2. Presence of unilateral erupted permanent mandibular second premolars.

3. Participants with caries in permanent mandibular second premolars.

4. Permanent mandibular second premolars clinically showing hypoplastic features.

The participant consent form and the participant information details (name, age, gender, occupation, address were collected. Direct oral examination was performed. The examinations were carried out using a dental mouth mirror and dental explorer. The pictures were taken using iPad. The number of cusp, groove pattern and occlusal morphologies of both left and right permanent mandibular second premolars were noted.

\section{RESULTS}

Table 1 and graph 1shows the general distribution of study population. In our study, out of 100 subjects 44 (44\%) were males and 56(56\%) were females.

Table 1 Distribution of gender

\begin{tabular}{ccc}
\hline S. No & Gender & Total \\
\hline 1 & Male & $44(44 \%)$ \\
2 & Female & $56(56 \%)$ \\
\hline
\end{tabular}

Table 2and graph 2 shows the distribution of number of cusps in permanent mandibular second premolars. Out of 200 teeth, about 111 teeth $(55.5 \%)$ of the mandibular second premolars showed 2 cusp pattern, 87 teeth (43.5\%) showed 3 cusp pattern and 2 teeth $(1 \%)$ showed 4 cusp pattern.

Table 2 Distribution of number of cusps in mandibular second premolars

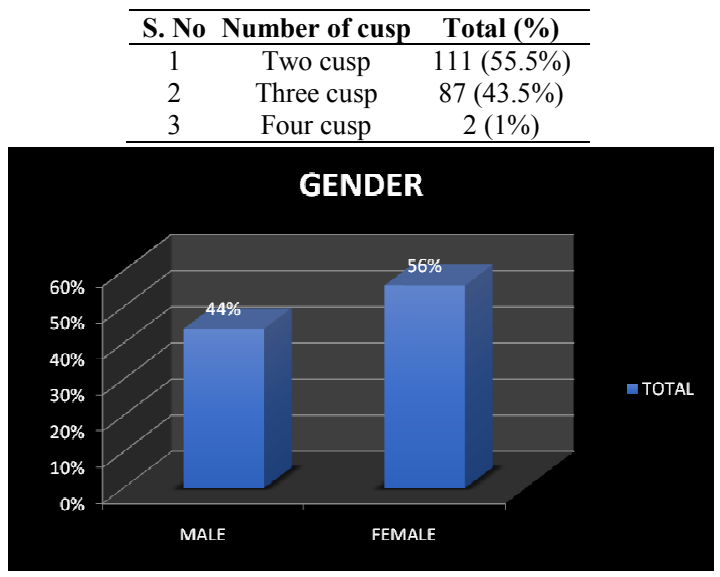

Figure 1 Distribution of gender
Table 3and graph 3 shows the distribution of types of groves in permanent mandibular second premolars. Out of 200 teeth, about 71 teeth $(35.5 \%)$ of the mandibular second premolars showed U shaped groove, 87 teeth $(43.5 \%)$ showed $\mathrm{Y}$ groove pattern, 39 teeth (19.5\%) showed $\mathrm{H}$ groove pattern and 3 teeth $(1.5 \%)$ showed straight groove pattern.

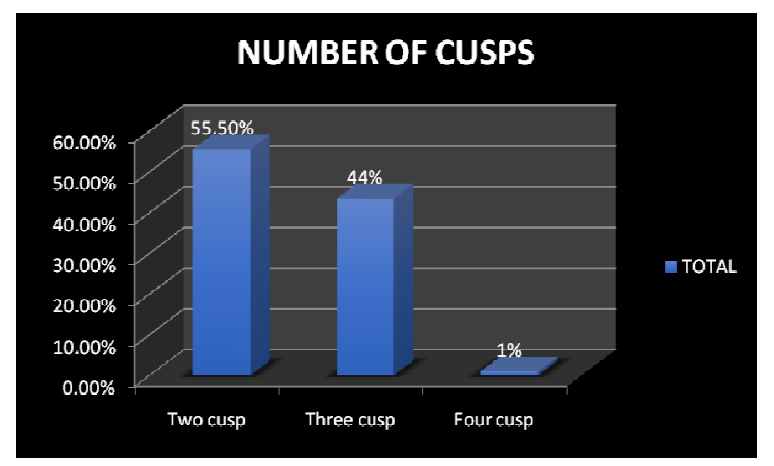

Figure 2 Distribution of number of cusp in mandibular second premolars

Table 3 Distribution of type of groove patterns in mandibular second premolars

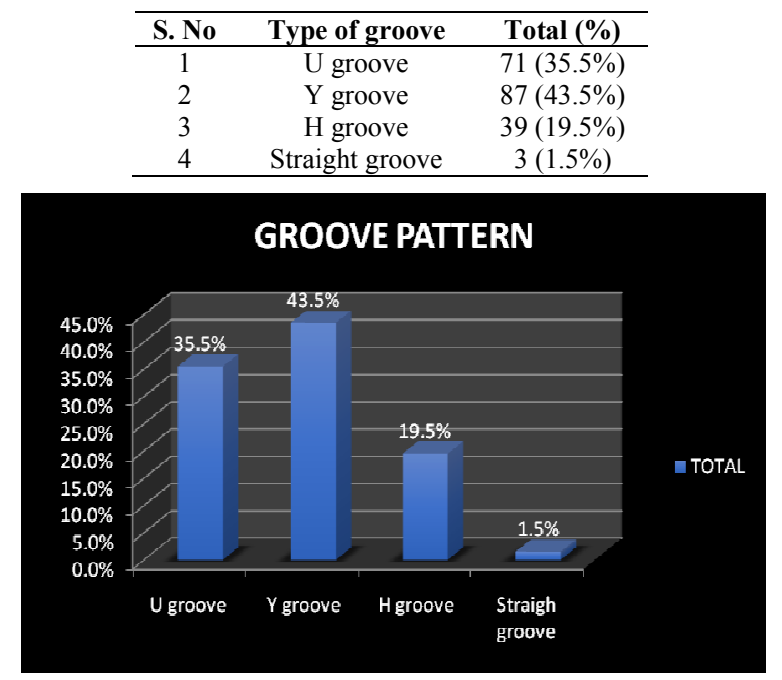

Figure 3 Distribution of types of groove patterns in mandibular second premolars

Table 4 and graph 4 shows the distribution of combination of cusps and grooves in permanent mandibular second premolars. Out of 200 tooth, about 55 teeth $(27.5 \%)$ were $2 \mathrm{U}$, 35 teeth $(17.5 \%)$ were $2 \mathrm{Y}, 18$ teeth $(9 \%)$ were $2 \mathrm{H}$ groove, 3 teeth $(1.5 \%)$ were straight groove, 16 teeth $(8 \%)$ were $3 \mathrm{U}, 50$ teeth $(25 \%)$ were $3 \mathrm{Y}, 21$ teeth $(10.5 \%)$ were $3 \mathrm{H}, 2$ teeth $(1 \%)$ were $4 \mathrm{Y}$. The $4 \mathrm{U}, 4 \mathrm{H}$ and 4 straight and 3 straight combinations were not seen.

Table 4 Distribution of combination of cusps and grooves in mandibular second premolars

\begin{tabular}{ccc}
\hline S. No & $\begin{array}{c}\text { Combination of } \\
\text { cusp and groove }\end{array}$ & Total (\%) \\
\hline 1 & $2 \mathrm{U}$ & $55(27.5 \%)$ \\
2 & $2 \mathrm{Y}$ & $35(17.5 \%)$ \\
3 & $2 \mathrm{H}$ & $18(9 \%)$ \\
4 & 2 straight & $3(1.5 \%)$ \\
5 & $3 \mathrm{U}$ & $16(8 \%)$ \\
6 & $3 \mathrm{Y}$ & $50(25 \%)$ \\
7 & $3 \mathrm{H}$ & $21(10.5 \%)$ \\
8 & 3 straight & $0(0 \%)$ \\
9 & $4 \mathrm{U}$ & $0(0 \%)$ \\
10 & $4 \mathrm{Y}$ & $2(1 \%)$ \\
11 & $4 \mathrm{H}$ & $0(0 \%)$ \\
12 & 4 straight & $0(0 \%)$ \\
\hline
\end{tabular}




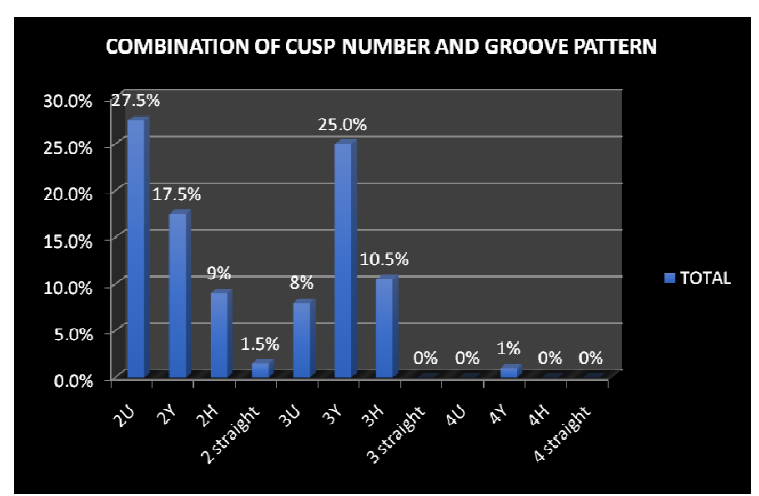

Figure 4 Distribution of combination of cusp and groove in mandibular second premolars

Table 5 and graph 5 shows the number of cusps in permanent mandibular second premolars in males. Out of 88 teeth of 44 males, about 54 teeth $(61 \%)$ showed two cusp pattern, 32 teeth $(36.3 \%)$ showed three cusp pattern and 2 teeth $(2.2 \%)$ showed four cusp pattern.

Table 5 Distribution of number of cusps in males in mandibular second premolars

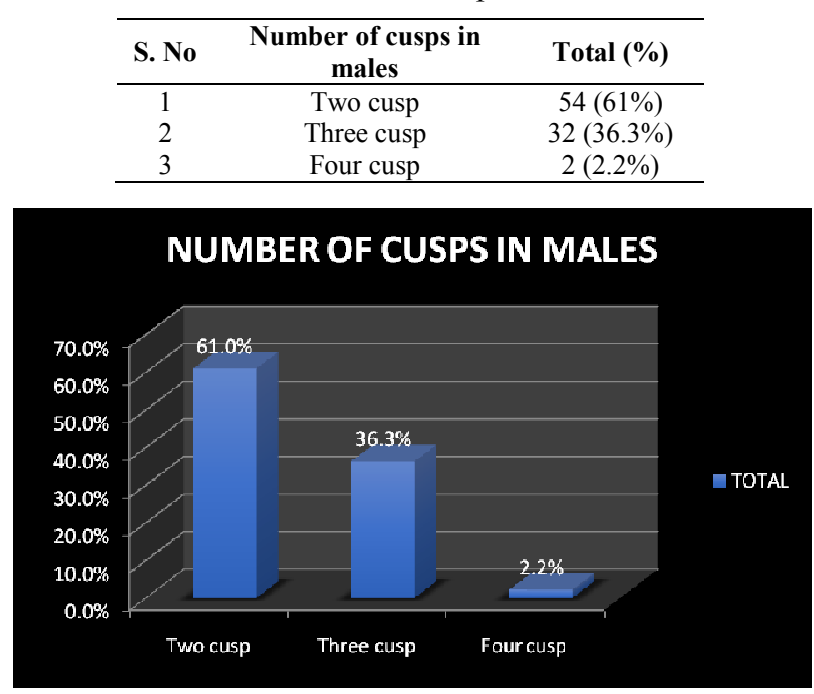

Figure 5 Distribution of number of cusp in mandibular second premolars of males

Table 6 Distribution of types of groove patterns in males in mandibular second premolars

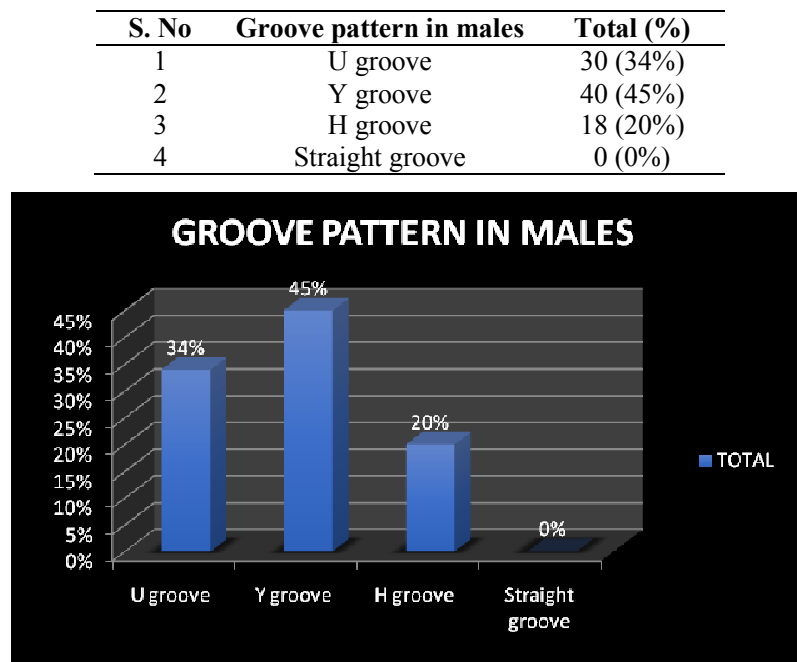

Figure 6 Distribution of groove pattern in mandibular second premolars in males
Table 6 and graph 6 shows the types of groove in permanent mandibular second premolars in males. Out of 88 teeth of 44 males, about 30 teeth (34\%) were U groove, 40 teeth $(45 \%)$ were $\mathrm{Y}$ groove, 18 teeth $(20 \%)$ were $\mathrm{H}$ groove and none showed straight groove.

Table 7 and graph 7 shows the distributional number of cusps in permanent mandibular premolars in females. Out of 112 teeth of 56 females, about 57 teeth $(51 \%)$ were two cusp and 55 teeth $(49 \%)$ showed three cusp pattern and none showed four cusp pattern.

Table 7 Distribution of number of cusps in females in mandibular second premolars

\begin{tabular}{ccc}
\hline S. No & $\begin{array}{c}\text { Number of cusps in } \\
\text { females }\end{array}$ & Total (\%) \\
\hline 1 & Two cusp & $57(51 \%)$ \\
2 & Three cusp & $55(49 \%)$ \\
3 & Four cusp & $0(0 \%)$ \\
\hline
\end{tabular}

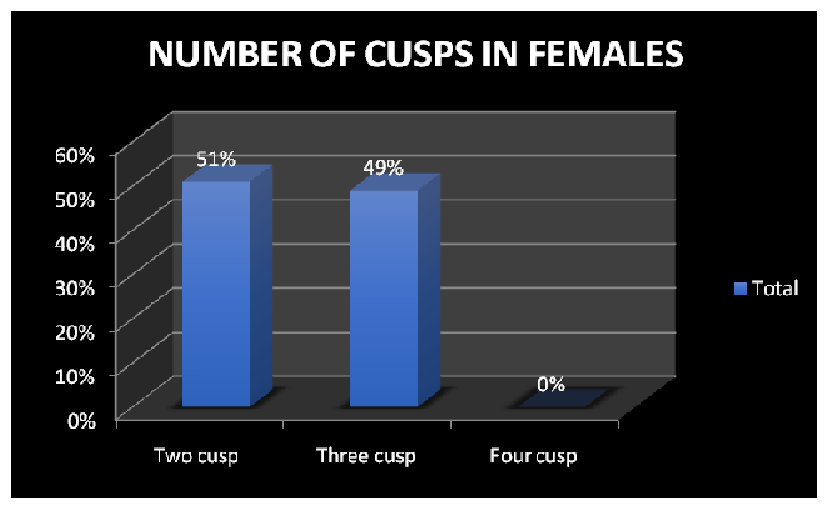

Figure 7 Distribution of number of cusp in mandibular second premolars in females

Table 8 and graph 8 shows the distribution of types of grooves in permanent mandibular second premolars in females. Out of 112 teeth of 56 females, about 41 teeth (36.6\%) were U groove, 47 teeth (41.9\%) were Y groove, 21 teeth $(18.7 \%)$ were $\mathrm{H}$ groove and 3 teeth $(2.6 \%)$ were straight groove.

Table 8 Distribution of types of groove patterns in mandibular second premolars in females

\begin{tabular}{ccc}
\hline S. No & $\begin{array}{c}\text { Groove patterns in } \\
\text { females }\end{array}$ & Total (\%) \\
\hline 1 & U groove & $41(36.6 \%)$ \\
2 & Y groove & $47(41.9 \%)$ \\
3 & H groove & $21(18.7 \%)$ \\
4 & Straight groove & $3(2.6 \%)$ \\
\hline
\end{tabular}

\section{GROOVE PATTERN IN FEMALES}

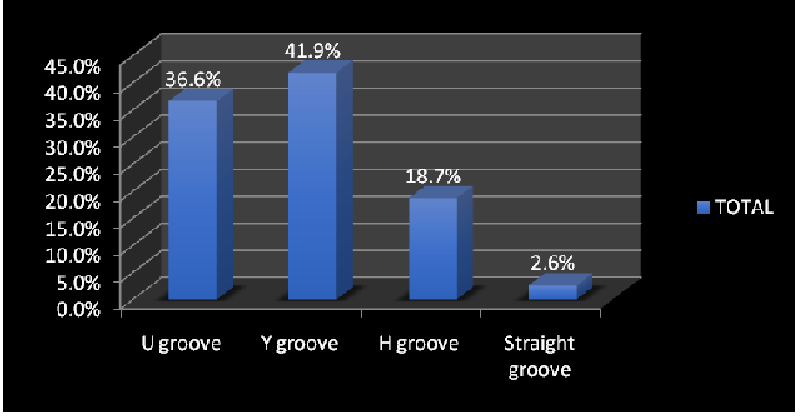

Figure 8 Distribution of types of groove pattern in mandibular second premolars in females 
Thestudy revealed that the predominant cusp pattern wastwo cusp pattern $(55.5 \%)$ and the predominant groove pattern was $\mathrm{Y}$ shaped $(43.5 \%)$. The predominance in the combination of cusp and groove pattern was $2 \mathrm{U}(27.5 \%)$. Among males, the predominant cusp pattern was bicuspid (61\%) and the predominant groove pattern was Y shaped (45\%). Among females, the predominant cusp pattern was bicuspid $(51 \%)$ and the predominant groove pattern was Y shaped (41.9\%).

\section{DISCUSSION}

Mandibular second premolars is one of those permanent teeth with diverse morphological features existing in different population $[4,5]$. That is why the knowledge of its type is very important from the clinical point of view so that not only it's other variants are identifiedfrom one another but also differentiate it from the second deciduous molar.

Thestudy of dental morphological characteristics and odontometry is important in anthropological research as it can provide information on the phylogenetic relationship between species, well as variations and diversities within a population [8]. Further more, knowing common variations in dental anatomy and morphology about each individual tooth can help in performing some dental treatments. Degree of expression and frequency of teeth in dentitions of different populations is different, which may help in forensic identification.

In our study, the predominant cusp typewas found to be two cusp $(55.5 \%)$. This was found to be in accordance to the study doneby Sunil.S \& Gopakumar.D who reported that bicuspids $(52.8 \%)$ were predominant in Kerala population. But the study done by Ash \& Nelson reported a higher Prevalence for the 3 cusp pattern in their study. Asrar et al study showed a predominance in tricuspid $(62.4 \%)$. Similarly, in BathBalogh.M and James fuller JL study the predominant pattern was tricuspid variety (55\%). (Table 9)

Table 9 Discussion table

\begin{tabular}{cccc}
\hline S. No & Studies & $\begin{array}{c}\text { Predominance of } \\
\text { cusp }\end{array}$ & $\begin{array}{c}\text { Predominant groove } \\
\text { pattern }\end{array}$ \\
\hline 1 & My study & Bicuspid $(55.5 \%)$ & Y shaped $(43.5 \%)$ \\
2 & Sunil \& Devi & Bicuspid (52.8\%) & U/Cresent shaped and \\
Gopakumarstudy & Y $(45.27 \%)$ \\
3 & Asrar Ahmed et al study & Tricuspid (62.4\%) & Y shaped \\
4 & Ash and Nelson study & Tricuspid & Y shaped \\
5 & Bath-Balogh. M and & Tricuspid & Y shaped \\
\hline
\end{tabular}

Regarding the groove patterns, the predominant groove pattern in our study was Y groove with $43.5 \%$. Asrar et al showed a higher prevalence of $\mathrm{Y}$ groove and Sunil.S \& Gopakumar.D study in Kerala population showed $U$ groove pattern and $\mathrm{Y}$ groove pattern (45.27\%). The study done by Ash \& Nelson study reported a higher prevalence of Y shaped groove. (Table 9)

\section{CONCLUSION}

Dental identification is an important identification tool in forensic odontology. Due to variants in permanent mandibular second premolars there is a difference of opinion regarding whether ethnicity influences dental morphology or not. Comparison of present study to other studies in literature showed that the prevalence pattern of cusp of carabelli was different in different populations. The variation may be due to ethnic and regional differences. More number of samples is needed for better evaluation and comparison.

\section{References}

1. Ash, M. \& Nelson, S. Wheeler's dental anatomy, physiology, and occlusion. 8th ed. Philadelphia, Elsevier Saunders, 2009. pp.239-61.

2. Ash MM, Nelson S. Wheeler's Dental Anatomy, Physiology, and Occlusion. 9th ed. Philadelphia: WB Saunders; 2011, p. 239-43.

3. Bath-Balogh M, Fehrenbach MJ. Occlusion in Dental embryology, Histology, and Anatomy. 3rd ed. Philadelphia: WB Saunders; 2011, p. 198-205.

4. Coro JC, Velasquez RL, Coro IM, Wheeler TT, McGorray SP. Relationship of maxillary 3-dimensional posterior occlusal plane to mandibular spatial position and morphology. Am J OrthodDentofacialOrthop. 2016; 150(1): 140-52.

5. Farooq J, Ahmed I, Gul-e-Erum, Iqbal SN. Relationship between tooth dimensions and malocclusion. J Pak Med Assoc. 2014; 64(6): 670-74.

6. Khan DB, Khan F, Khan H. Frequency of bicuspid and tricuspid form of mandibular second premolar at Khyber College of Dentistry, Peshawar. J. Med. Sci. 2013; 21(3): 118-20.

7. LohHS. Coronal morphology of the mandibular second premolar in the Singaporean Chinese. Aust Dent J. 1993; 38(4): 283-86.

8. Sharma, J. C. Dental morphology and odontometry of the Tibetan immigrants. Am. J. Phys. Anthropol., 61(4):495- 505, 1983.

9. Sunil.Sand Gopakumar.D. Prevalence of the two variants of mandibular second premolars in Kerala population. Int. J. Odontostomat., 6(3):375-377, 2012.

10. Fuller, J. L.; Denehy, G. E. \&Schulein, T. M. Concise dental anatomy and morphology. $4^{\text {th }}$ ed. Iowa, University of Iowa College of Dentistry, 2001. pp.8698.

\section{How to cite this article:}

Priyadharshini M and Don K. R (2017) ' Prevalence Of Two Variants Of Permanent Mandibular Second Premolars', International Journal of Current Advanced Research, 06(04), pp. 3541-3544.

DOI: http://dx.doi.org/10.24327/ijcar.2017.3544.0311 